\title{
AVALIAÇÃO DE TRADUÇÕES: A VEZ E A VOZ DO APRENDIZ
}

\author{
Marcia A. P. Martins* \\ Maria Paula Frota*
}

\begin{abstract}
RESUMO: Segundo especialistas da área da educação, a avaliação constitui tema ao mesmo tempo polêmico e relevante, consideradas suas implicações pedagógicas, psicológicas e sócioeconômicas. Observa-se, entre professores, a tendência a realizarem, sem maior reflexão, práticas avaliatórias de natureza objetivizante na busca de uma avaliação exata e justa. Neste trabalho, faremos a crítica a esse paradigma, ao lado da qual apresentaremos algumas alternativas envolvendo interação e negociação, processos que levam em conta os sujeitos $e$ as circunstâncias implicadas na produção dos trabalhos avaliados.
\end{abstract}

UNITERMOS: educação; ensino de tradução; avaliação.

Como indica a literatura da área ${ }^{1}$, dois aspectos se destacam da pedagogia tradicional de tradução, ainda comumente adotada em escolas do mundo inteiro:

- o apagamento da teoria (manifestado através da crença de que tradução se aprende traduzindo, ou seja, de que essa prática prescinde do exercício reflexivo) e

- a centralidade do lugar ocupado pelo professor (o qual sequer se dá conta, em geral, de que concentra em si os papéis de cliente, público-alvo e crítico).

(*) Pontifícia Universidade Católica, Rio de Janeiro, Brasil.

(1) Ver Rosemary Arrojo. O signo desconstruído. São Paulo, Pontes, 1992 e Tradução, desconstrução e psicanálise. Rio de Janeiro, Imago, 1993; Anais do III Encontro Nacional de Tradutores. Porto Alegre, UFRGS, 1988. 
A dinâmica usada nos cursos de tradução é, com maior freqüência, a da prática de tradução comentada, onde se comparam as traduções previamente feitas pelos aprendizes. As discussões são conduzidas pelo professor, que fornece os parâmetros para a avaliação das diversas soluções apresentadas, parâmetros que, via de regra, limitam-se a ter um caráter lingüístico, no sentido estrito do termo. Nesse tipo de abordagem, que privilegia o produto final da tradução e não o processo tradutório, não há oportunidade para que os alunos justifiquem suas escolhas, sobretudo quando não coincidem com aquelas consideradas boas ou certas pelo professor, o qual desempenha o papel de juiz.

Dentro desse contexto, as três traduções abaixo símbolo produzidas por alunos de um curso introdutório, a partir do livro infantil Chicken soup with rice ${ }^{2}$ - não seriam consideradas igualmente aceitáveis. De um modo geral, não havendo especificações prévias, a versão mais próxima do texto-fonte costuma ser privilegiada e valorizada pelos professores, enquanto outras, que dele se afastam, são, em princípio, descartadas, ou consideradas adaptações.

\begin{tabular}{|l|l|}
\cline { 2 - 2 } \multicolumn{1}{c|}{} & \multicolumn{1}{c|}{ Tradução 1 } \\
\hline JANUARY & JANEIRO \\
$\begin{array}{l}\text { In January } \\
\text { it's so nice } \\
\text { while slipping } \\
\text { on the sliding ice } \\
\text { to sip hot chicken soup with } \\
\text { rice. } \\
\text { Sipping once } \\
\text { sipping twice } \\
\text { sipping chicken soup } \\
\text { with rice. }\end{array}$ & $\begin{array}{l}\text { todos nós adoramos } \\
\text { tomar canja de galinha } \\
\text { enquanto patinamos. } \\
\text { um gole dali, } \\
\text { cuidado com o gelo } \\
\text { para não cair. }\end{array}$ \\
\hline
\end{tabular}

(2) Children's Dictionary (Monolingual). Boston: Houghton-Mifflin, 1979, Introdução de Stephen Krensky.

TradTerm, 4(1), $1^{\circ}$ semestre de 1997 , p. 69-84 


\begin{tabular}{|l|l|}
\hline \multicolumn{1}{|c|}{ Tradução 2 } & \multicolumn{1}{c|}{ Tradução 3 } \\
\hline JANEIRo & JANEIRO \\
Mês de brincadeiras, & Janeiro é bom demais. \\
Na areia e no mar. & De férias com os irmãos, \\
Mas gostoso mesmo & Vovô, vovó e meus pais. \\
É ver navios, & Brincar na beira da praia, \\
Tomando muito sorvete & Fazer castelos de areia, \\
Até se fartar. & Sabendo que, na barraca, \\
E a canja, meu senhor, & No isopor, a sobrar, \\
Quentinha, nesse calor? & Tem bolo, refresco de jaca, \\
Ora, ora, que coisa louca, & E sombra pra descansar. \\
Pode ser fria, morna, & \\
Ou geladinha. & \\
Só não pode faltar... & \\
A canja de galinha! & \\
\hline
\end{tabular}

O livro do qual o pequeno poema acima foi extraído apresenta doze rhymes, cada qual referente a um mês do ano, caracterizando-os quanto a condições climáticas, comemorações nacionais, período letivo ou de férias, e assim por diante. Quando o utilizamos, os alunos receberam o conjunto dos poemas para traduzir, sem que lhes fizéssemos qualquer recomendação. O nosso intuito foi o de levá-los, logo ao início do curso, a defrontaremse com a diferença, com a multiplicidade de traduções que aquele original nos pareceu especialmente capaz de provocar. Vindo ao encontro de nosso objetivo, os alunos apresentaram, na aula seguinte, traduções as mais diversas. De acordo com o senso comum, e mesmo com grande parte da crítica, reagiram de forma a não aceitar traduções que divergissem, em um grau mais acentuado, daquelas que cada qual havia feito. Os seus textos claramente derivavam de diferentes motivações e estratégias, sem que delas, no entanto, os alunos tivessem consciência suficiente para justificar suas opções. Como discutiremos em maior minúcia a seguir, essa atitude que desconhece a relevância do contexto de cada tradução constitui ponto central a ser enfrentado por uma nova metodologia de ensino e de avaliação em nossa área. 
Com a escolha das três traduções apresentadas, procuramos aqui ilustrar resultados que, embora bastante distintos, julgamos aceitáveis, dependendo dos objetivos definidos para cada um deles. Em conjunto, fomos construindo contextos hipotéticos coerentes com os caminhos tomados. Assim, uma tradução como a primeira acima, se adequaria ao objetivo de ensinar a crianças cariocas ou brasileiras características de um outro país, visando mostrar-lhes que referências ou circunstâncias nossas, como o calor, as férias e o carnaval que aqui animam os meses de janeiro e fevereiro, inexistem nos Estados Unidos, ou mesmo no hemisfério norte. Já a segunda tradução, que poderia ter o mesmo cliente que a anterior - uma secretaria de educação, por exemplo - e o mesmo público - crianças, digamos, na faixa de seis a oito anos -, teria como objetivo ensinar-lhes a caracterizar os meses vividos em nossa cultura e região. A terceira tradução, por sua vez, tem um caráter menos genérico, e talvez seja vista, por muitos, como uma adaptação, inclusive por afastar-se do núcleo temático do refrão; no entanto, poderia ser considerada satisfatória em um contexto onde se quisesse fugir de marcas culturais estereotipadas, substituindo-as por experiências mais pessoais, individualizadas. Dessa forma, acreditamos ter sido possivel marcar a necessidade imprescindivel de nos situarmos, ainda que hipoteticamente, em relação às condições que minimamente norteiam o trabalho profissional de um tradutor.

À luz da nova epistemologia que permeia estudos contemporâneos e que parte do principio de que não há uma realidade independente daquele que a percebe, a filosofia de ensino vem se modificando, abrindo espaço para a pluralidade interpretativa. No caso do ensino da tradução, essa nova epistemologia levou a uma ênfase no processo do fazer tradutório como forma de abrir espaço para os aprendizes nas discussões em sala - cada qual não mais apenas apresentando o seu trabalho final ou superficialmente criticando os dos colegas, preocupados com a melhor tradução, mas fundamentando as escolhas feitas, com base nos critérios e objetivos especificamente definidos para suas traduções (Martins 1993c, p. 52).

Essa reestruturação da dinâmica em sala de aula tem, evidentemente, um grande impacto sobre os critérios e metodologias 
de avaliação. A esse respeito, é importante fazer a distinção entre os dois níveis de avaliação implicados em uma situação de ensino formal: aquela mais ampla e constante, da qual todos os aprendizes participam, através de comentários relativos aos seus próprios desempenhos e aos dos demais, e a avaliação específica de trabalhos escritos, em uma situação restrita à sua leitura pelo professor. Essa nova atitude também opera um deslocamento do professor para o aluno no que tange ao estabelecimento de parâmetros norteadores das escolhas feitas. Essa definição de parâmetros vincula-se à noção de contextualização da tradução, ou seja, à definição do público-alvo da tradução, do tipo de veículo em que será lida, do seu objetivo, etc. E é à luz dessa contextualização (Para quem? Por quê? Como?), definida pelo tradutoraprendiz isoladamente ou em conjunto com a turma, que a critica às suas escolhas e estratégias pode ser feita. Esse tipo de avaliação centrada na experiência vivida ao longo do fazer tradutório e, portanto, em cada aprendiz individualmente, levaos a desenvolver sua capacidade de (auto)crítica e de reflexão, dando-lhes, conseqüentemente, maior segurança e independência.

Considerando, por um lado, a natureza do tema aqui em questão e, por outro, a escassez de trabalhos que o enfoquem na literatura sobre o ensino da tradução ${ }^{3}$, buscou-se, na área da educação, um suporte que pudesse esclarecer sobre o que já foi pensado e proposto relativamente ao tema geral da avaliação.

(3) A avaliação educacional é colocada em plano secundário não só pelos professores e pesquisadores da área de estudos da tradução como pelas instituições de ensino superior em geral, cujos programas de formação de docentes abordam apenas precariamente esse assunto nas disciplinas de prática pedagógica. No âmbito da tradução, pode-se fazer essa constatação em programas e anais de congressos. A título de ilustração, citaremos alguns eventos na área realizados nos últimos dez anos, indicando o total de trabalhos apresentados ou publicados e quantos destes abordavam a questão da avaliação: (1) Anais do Terceiro Encontro Nacional de Tradutores, sobre o tema $O$ ensino da tradução, ocorrido em Porto Alegre, em agosto de 1987: 31 comunicações apresentadas, apenas uma sobre avaliação; (2) Anais da First Language International Conference on Teaching Translation and Interpreting, realizada em 
Em artigo recente, a educadora Vera Tavares de Souza (1994) afirma que "poucos temas na educação geram tanta emoção e controvérsia como a avaliação da aprendizagem" (pp. 1314); mas que, ao lado disso, e talvez por isso, ela também constitui um tema muitas vezes negligenciado. A pesquisadora relata, ainda, que há grandes divergências entre os especialistas sobre o valor da avaliação: enquanto que, para uns, trata-se de uma ferramenta construtiva e motivadora, que gera competição saudável, melhoria e inovações no ensino, para outros é uma atividade destrutiva, que ameaça a espontaneidade, cria uma atmosfera de tensão e paralisa a criatividade. Podemos, assim, constatar a relevância não só da implicação estritamente pedagógica da avaliação, como de suas implicações psicológicas e socioeconômicas.

Ainda que alguns atribuam à avaliação um caráter intimidador, o fato é que os professores têm de avaliar. A estrutura educacional exige isso, bem como a sociedade de uma maneira geral. A avaliação é um gesto que está presente nas mais variadas situações de vida. Cabe ao docente desenvolver, de comum acordo com os alunos, formas de avaliação que propiciem um feedback mais construtivo e que estejam sintonizadas com

Elsinore, Dinamarca, em junho de 1991: 34 trabalhos publicados, nenhum sobre o tema em questão; (3) Programa da conferência internacional Translation Studies: An Interdiscipline, realizada em Viena, em setembro de 1992: 175 trabalhos apresentados, apenas dois sobre avaliação; (4) Anais da Second Language International Conference on Teaching Translation and Interpreting, realizada em Elsinore, Dinamarca, em junho de 1993: 35 trabalhos publicados, quatro sobre o tema em foco (dois sobre a avaliação de traduções e dois sobre a avaliação da qualidade do desempenho do intérprete simultâneo); (5) Anais da Third Language International Conference on Teaching Translation and Interpreting, realizada em Elsinore, Dinamarca, em junho de 1995: 31 trabalhos publicados, quatro sobre avaliação (também divididos equitativamente entre a qualidade de traduções e a de interpretações simultâneas); e, por fim, (6) Programa do EST Congress, realizado em Praga, República Checa, em setembro de 1995: 82 trabalhos apresentados, quatro sobre ensino e avaliação. 
as epistemologias e as filosofias de ensino do seu tempo. Em seu livro Fourth generation evaluation (1989), Egon Guba e Yvonna Lincoln procuram sintetizar as transformações conceituais da avaliação, apresentando-as através de quatro gerações. A primeira consiste na mensuração, a qual enfatiza medidas e testes; a segunda, na descrição, centrada na análise de resultados obtidos com relação aos objetivos propostos; a terceira se faz através do julgamento de valor, no qual o avaliador exerce o papel de juiz; e a quarta constitui-se como negociação, envolvendo aspectos humanos de natureza sociocultural e político-ideológica.

Dentro dos objetivos e limites deste trabalho, não cabe comentar esse percurso conceitual, mas sim destacar características da chamada quarta geração, única que vem ao encontro de nossas expectativas. Sua ênfase na negociação atende às aspirações geradas por esse atual momento pós-moderno, seja no modo de conceber a linguagem, a tradução ou o ensino. Ela se constitui como um modo de avaliação em que o aprendiz é valorizado, sendo rejeitados os modelos que desconsideram os sujeitos nas suas diferenças. A avaliação negociada pauta-se, fundamentalmente, por duas diretrizes:

- dar voz ao aprendiz, ouvi-lo explicitar suas motivações, dúvidas e objetivos, e

- dar ênfase não só à avaliação do aprendiz pelo professor, mas também à auto-avaliação e à avaliação dos professores e dos cursos pelos aprendizes.

Como aponta Tavares de Souza (1994), "há uma ênfase cada vez maior nas técnicas tanto de auto-avaliação quanto de avaliação da atuação do docente e dos instrumentos/estratégias que levam o aprendiz ao domínio da aprendizagem" (p. 15). O professor deixa de ser o único avaliador, dividindo essa tarefa com os alunos. A conseqüência disso é o descentramento da figura do juiz, originalmente encarnada pelo docente, a qual passa a ser compartilhada por todos os membros da turma.

Vale observar que esse estudo de Guba \& Lincoln não se dirige a professores interessados em renovar sua prática avaliatória, mas, fundamentalmente, a avaliadores profissionais, os 
quais formam uma categoria reconhecida há alguns anos nos Estados Unidos. Os autores tratam, portanto, não da avaliação de trabalhos discentes, mas daquela que tem como objeto bens e serviços oferecidos por empresas em geral. Isso, no entanto, não nos impediu de aí encontrar formulações teóricas e encaminhamentos práticos passiveis de serem trazidos para o contexto de cursos universitários.

Um aspecto central na proposta de Guba \& Lincoln, que também constitui um dos fundamentos básicos da reformulação aqui apresentada, é a critica radical às posturas cientificistas, caracterizadas pela adoção de técnicas estatísticas de avaliação empregadas por um único avaliador. Por outro lado, é valorizada a definição de critérios calcados em valores sociais e ideológicos que contemplem possiveis singularidades. O processo avaliatório e seus resultados são vistos não como descrições objetivas de fatos, mas como construções interpretativas, engendradas na interação de todos os agentes envolvidos. Essas construções são encaradas como resultantes de valores dos sujeitos construtores, valores que podem ser comuns ou distintos - no último caso, assumindo importância capital a negociação das diferenças.

Avaliações e avaliadores, construções e construtores estão indissoluvelmente vinculados aos contextos sócio-históricos que os constituem. Esses contextos, por sua vez, são também vistos como construções. Ou seja, tanto os objetos avaliados como aqueles que avaliam e seus contextos são concebidos como construções resultantes de percepções ou interpretações possivelmente conflitantes, não podendo, assim, ser considerados como verdadeiros em um sentido absoluto. Trata-se de construções nas quais o sujeito está necessariamente implicado, e que, portanto, não devem ser vistas como objetivas justamente o ponto nuclear criticado no início deste trabalho, relativo às visões tradicionais tanto do ato de traduzir quanto do ato de ensinar.

Ao colocarem-se contrários à centralização do poder avaliatório, os autores insistem na divisão desse poder como fator responsável pela emancipação do aprendiz, visto que este assume maior responsabilidade pelo que faz, através da fundamentação e crítica de seu trabalho. Cada avaliação é encarada como parte de um processo mais amplo, no qual os atores envol- 
vidos interagem e negociam constantemente, de acordo com uma ética que também se distingue daquela que é exercida pelos avaliadores convencionais. A ética que Guba \& Lincoln propõem, coerentemente com os seus princípios, prioriza as diferenças, mas sugere, em paralelo, uma atitude de respeito e parceria na elaboração, implementação e demais ações que participam e resultam de uma avaliação. A valorização das diferenças e da firmeza de convicções não deve confundir-se com atitudes de intransigência, devendo-se evitar o risco de um individualismo radical que acabaria por trazer de volta uma postura tão autoritária quanto aquela que de início se rejeitou.

Esta metodologia de avaliação distingue-se de toda uma tradição pautada em formas padronizadas de avaliação de objetivos. É contra essa mesma tradição que se voltam as teorias de tradução pós-estruturalistas, as quais reivindicam a necessária inscrição do tradutor nos textos que lê/escreve e negam a possibilidade de uma atuação neutra, que vise reproduzir significados, intenções e efeitos exteriores a ele.

Mas como colocar em prática essa proposta de avaliação, não apenas no caso das discussões rotineiras em sala de aula, mas no caso das traduções que, feitas pelos aprendizes, devem ser lidas e julgadas? Antes de mais nada, a avaliação, também nesse contexto, deve levar em conta uma série de fatores (Martins 1993c, p. 53):

- os objetivos do tradutor-aprendiz em cada tarefa específica, para que o resultado final seja julgado com referência aos mesmos, e não isoladamente;

- as decisões tomadas pelo tradutor-aprendiz ao longo do processo e suas respectivas motivações; e

- os procedimentos usados e a adequação dos mesmos a situações específicas.

Como tornar explícitos todos esses detalhes, no contexto particular de avaliação de um trabalho escrito? Os aprendizes são incentivados a acompanharem suas traduções de comentários que expliquem, sempre que julgarem necessário, as estratégias, as dificuldades e as diferentes alternativas com que se confrontaram ou que empregaram. Esses comentários servirão 
para fundamentar e justificar as suas escolhas, no momento em que aquele texto em particular estiver sendo lido isoladamente pelo professor.

Assim, ao avaliar os trabalhos, o professor terá mais subsídios para entender o processo vivenciado pelo aprendiz, os critérios que nortearam suas escolhas e os objetivos que pretendia alcançar. O professor poderá ampliar esse conhecimento, solicitando novos esclarecimentos acerca de trechos que gostaria de discutir mais profundamente antes de chegar a uma avaliação. É importante, no entanto, que assinale tais trechos e indique o motivo do seu gesto, como forma de orientação. Poderá, por exemplo, solicitar ao aprendiz que justifique o recurso a uma adaptação cultural, a escolha de uma determinada metáfora ou o uso de um item lexical aparentemente em desacordo com o registro que prevalece no texto. Ou, ainda, recomendar que seja feita uma revisão dos acentos, da ortografia, de determinados casos de regência ou de concordância, ou mesmo de aspectos formais mais amplos como a fluência/opacidade do texto.

Dessa forma, inicia-se um diálogo com os aprendizes que pode ter vários turnos, até que os dois interlocutores sintam-se suficientemente informados sobre os propósitos e critérios que regeram aquela determinada tradução. Muitas vezes, o aprendiz só vai se dar conta de alguns desses aspectos durante o diálogo com o professor, na medida em que é solicitado a refletir sobre eles e a explicitá-los. Mesmo que, muitas vezes, não se chegue a um consenso, a própria articulação das diferenças já é um objetivo que vale a pena alcançar. Não se entende, aqui, o termo negociar como fazer concessões, mas explicitar, discutir, entender a pluralidade e as divergências e, talvez, mudar de ponto de vista. Ao valorizar a diferença e a negociação, dá-se aos aprendizes o direito de colocarem na mesa, para consideração, suas questões, expectativas e interesses. Sem essas informações, o professor não terá condições de realizar uma avaliação que respeite a nova ética.

Para ilustrar esta proposta, será mostrado um exemplo de uma avaliação negociada e interativa.

Um dos primeiros exercícios feitos pelos alunos da disciplina Tradução Técnica I, recentemente, foi a tradução de The history of the English language, que introduz uma outra publica- 
ção infanti1 ${ }^{4}$, neste caso, de natureza diversa. Antes de darmos início à tarefa, definimos variáveis importantes para fundamentar a formulação de critérios decisórios e orientar as escolhas a serem feitas, obtendo-se o seguinte quadro:

\begin{tabular}{|l|l|}
\hline Cliente da tradução: & Editora de livros infantis. \\
\hline Veículo: & $\begin{array}{l}\text { Dicionário Infantil da Língua Inglesa (bilín- } \\
\text { güe - inglês/português). }\end{array}$ \\
\hline Público-alvo: & Crianças de 10 a 15 anos, aproximadamente. \\
\hline Finalidade: & $\begin{array}{l}\text { Oferecer a crianças brasileiras que estu- } \\
\text { dam inglês um dicionário bilingüe, com } \\
\text { introdução e verbetes escritos em lingua- } \\
\text { gem adequada à faixa etária do público- } \\
\text { alvo previsto e, quando possível, com } \\
\text { exemplos adaptados à cultura de chegada. }\end{array}$ \\
\hline
\end{tabular}

Uma vez definidas essas variáveis, procedeu-se à tradução do texto, cujo parágrafo inicial reproduzimos abaixo:

\section{THE HISTORY OF THE ENGLISH LANGUAGE}

Language is something that most of us take for granted. Words seem to appear automatically in our heads; sentences pop out at our request. We hardly think about how and why we choose them. We read and write, speak and listen, as though we have done it always. This is not true, of course. We are not born with a language at the tip of our tongues, nor do we put on a language like a new winter coat. Learning a language is more like gathering leaves in October. We rake them up, either deliberately or at random, watching the pile grow larger as the leaves fall in ever increasing numbers.

(4) Children's Dictionary (Monolingual). Boston: Houghton-Mifflin, 1979, Introdução de Stephen Krensky. 
Foram feitas traduções bastante diferentes do segmento em questão, em que pesem a contextualização e os parâmetros consensualmente estabelecidos. Para ilustrar o processo de avaliação negociada, reproduziremos uma das traduções apresentadas:

\section{A HISTÓRIA DA LINGUAGEM}

A maioria das pessoas acha que a lingua é algo inato. Palavras parecem surgir automaticamente em nossas mentes; frases saltam ao nosso comando. Dificilmente pensamos em como e por que as escolhemos. Lemose escrevemos, falamos e ouvimos, como se sempre tivéssemos feito isso. É claro que não é verdade. Nós não nascemos com um alfabeto na ponta da lingua, nem vestimos um idioma como se ele fosse um biquini novo. Aprender uma língua é a mesma coisa que mudar de cor no verão. Pegamos sol, deliberada ou involuntariamente e observamos a pele ficar cada dia mais bronzeada. (FPM)

No processo de avaliação do segmento acima, sem implicar a atribuição de notas ou conceitos, foram feitas as seguintes observações:

\begin{tabular}{|cl|}
\hline 1 & Reflita sobre o título e comente a sua opção. \\
2 & Reveja e comente a ausência de artigos. \\
3 & Comente a escolha da palavra alfabeto. \\
4 & Reveja a pontuação do último período. \\
5 & $\begin{array}{l}\text { Você não acha que há uma estranheza muito } \\
\text { maior em vestir um idioma do que em to puton a } \\
\text { language? }\end{array}$ \\
& $\begin{array}{l}\text { Pesquise e reflita sobre a diferença de uso des- } \\
\text { sas expressões. }\end{array}$ \\
6 & Justifique a imagem do bronzeamento. \\
\hline
\end{tabular}

A aluna, por sua vez, após ler os comentários acima e analisar o seu trabalho à luz dos mesmos, formulou uma réplica da qual reproduzimos uma parte:

TradTerm, 4(1), $1^{\circ}$ semestre de 1997 , p. 69-84 
1 Escolhi como título "A História da Linguagem" porque esta foi a forma neutra que encontrei para traduzi-lo, já que a abordagem segundo a qual a tradução foi realizada privilegia a cultura de chegada e, portanto, a língua portuguesa, e não a inglesa (como no título original). No entanto, se fosse refazer a tradução, usaria "A História da Língua", pois acho que língua está mais de acordo com o assunto do texto.

2 As duas situações em que pude perceber a ausência de artigo estão na segunda frase. Em ambos os casos, não usei o artigo para que $p a-$ lavras e frases tivessem um sentido mais amplo e genérico. Após rever minha tradução, insisto na ausência de artigo, pois não quero determinar os substantivos em questão.

$3 \quad[\ldots]$

$4 \quad[\ldots]$

$5 \quad[\ldots]$

6 A imagem usada no texto original (juntar folhas) dá uma idéia de gradação. Como a tradução tinha como meta a cultura de chegada, ou seja, o Brasil, quis passar uma imagem bem brasileira, que, no entanto, não perdesse a idéia de gradação. Por isso usei bronzeamento, pois ninguém fica bronzeado da noite para o dia; é necessário que se vá à praia vários dias seguidos para que esse objetivo seja atingido.

(FPM)

O primeiro item da réplica deu origem à seguinte tréplica por parte do professor: 
1 O seu comentário sugere não só um desconhecimento acerca dos conceitos lingua e linguagem, como também a falta de uma leitura integral do texto antes de começar a traduzi-lo, na medida em que a diferença entre os dois conceitos fica bastante nítida mais adiante. Faça, para a próxima aula, uma pesquisa sobre os conceitos em questão, leia o texto na íntegra e reveja novamente a sua tradução.

Nesse momento, já se pode atribuir uma nota ou conceito ao trabalho do aluno, o qual, mais uma vez, terá espaço para negociação. É importante dizer que, embora o professor divida com o aprendiz a responsabilidade não apenas pela avaliação mas também pelo planejamento e desenvolvimento do curso, ele não pode se furtar a ocupar um lugar diferenciado em sua relação com os alunos. Não propomos, aqui, a extinção do papel docente, mas uma crítica do modo como ele é historicamente desempenhado e a implementação de mudanças. Sendo assim, consideramos que o professor deve saber conduzir o curso de uma forma negociada, sem, contudo, deixar de assumir uma autoridade pela qual é institucionalmente responsável - autoridade essa que propicia, aos aprendizes, a vivência de uma relação assimétrica, análoga àquela que experimentarão no mercado de trabalho. Com isso, elimina-se a possibilidade de uma negociação que não chegue a termo, de um ir-e-vir sem fim.

A implementação dessa pedagogia não é simples. Os estudantes com freqüência relutam em aceitar tanto um papel que os levará a trabalhar mais, quanto uma figura de professor que não se comporta de acordo com aquele padrão a que estão acostumados, o qual se pauta pela exigência de respostas imediatas e definitivas. O professor, por sua vez, pode inicialmente ressentir-se tanto de reações negativas, por parte dos alunos, à metodologia adotada, como de dificuldades inerentes ao seu próprio processo de adaptação à nova postura.

Contudo, consideramos que, com esse método, todos ganham: o aprendiz, porque é levado a pensar criticamente o seu 
trabalho e a buscar novos conhecimentos, através de pesquisas e consultas que se vê motivado a fazer; o professor, porque se sente muito mais pleno no exercício de sua função educadora, ao compartilhar com o aluno a possibilidade de múltiplas leituras, questionamentos e soluções; e o mercado de trabalho, porque passa a contar com profissionais mais conscientes e capazes de adequar suas estratégias a situações específicas. Além disso, acreditamos que a avaliação como negociação contribui para desenvolver a segurança e o aparato (auto)crítico do aprendiz, facilitando a realização de um dos principais objetivos educacionais. Como diz Tavares de Souza (1994), "a essência da educação é a mudança, e um dos seus objetivos mais importantes é ensinar a pensar eficiente e criticamente" (p. 13).

A consciência do papel fundamental da avaliação no contexto das atividades educacionais enfatiza a necessidade de um aprofundamento do estudo sobre o tema da avaliação em geral e da sua aplicação prática à pedagogia da tradução, a qual começa a despertar considerável interesse por parte de instituições no mundo inteiro, em decorrência da recente valorização do ensino formal da tradução.

\section{Referências Bibliográficas}

ARROJO, R. (1993) Desconstrução, psicanálise e o ensino de tradução. In: Tradução, desconstrução e psicanálise. Rio de Janeiro, Imago, pp. 133-150.

FROTA, M.P. (1990). Tradução e análise de discurso. In: Anais do V Encontro Nacional da ANPOLL, pp. 582-586.

FROTA, M.P. \& MARTINS, M.A.P. (1995) A avaliação nos cursos de tradução: com a palavra os aprendizes. Comunicação apresentada por ocasião da IV Semana de Estudos Anglo-Germânicos, UFRJ, Rio de Janeiro, 22-26 de maio (inédita).

GUBA, E. \& LINCOLN, Y. (1989) Fourth generation evaluation. Newbury Park, California, Sage.

MARTINS, M.A.P. (1993a) On Translation Criticism. In: Koinè: Quaderni di ricerca e didattica sulla traduzione e l'interpretazione (vol. especial: Traduzione e Riscrittura, pp. 71-80). Misano Adriatico: Istituto San Pellegrino.

TradTerm, 4(1), $1^{\circ}$ semestre de 1997, p. 69-84 
MARTINS, M.A.P. (1993b) For a process-oriented methodology in translation teaching. In: PaLavra, 1: pp.122-124. Rio de Janeiro, PUCRio.

MARTINS, M.A.P. (1993c) Processo vs. produto: a questão do ensino da tradução. In: Trabalhos em linguística aplicada, 20: pp. 49-54. Campinas, Unicamp/IEL.

MARTINS, M.A.P. (1993d) Re-avaliando a avaliação (resumo). In: Anais do VII Encontro Nacional da ANPOLL (Porto Alegre, maio de 1992). Goiânia, GO, pp. 989-990.

MARTINS, M.A.P. \& FROTA, M.P. (1994) A importância da determinação do contexto nas aulas de prática de tradução. Texto apresentado em mesa-redonda sobre ensino de tradução realizada como parte das atividades do Grupo de Trabalho de Tradução no IX Encontro Anual da ANPOLL, Caxambu, MG (inédito).

ORLANDI, E. (1988) Discurso e leitura. Campinas, Cortez.

PAES, J. P. (1990) Sobre a crítica de tradução. In: Tradução: a ponte necessária. São Paulo, Ática, pp. 109-118.

VIANNA, H. M. (1992) Avaliando a avaliação: da prática à pesquisa. Estudos em avaliação educacional. São Paulo, no 5, jan./jun., pp. 55-61.

TAVARES DE SOUZA, V. (1994) Avaliação da aprendizagem. In: Ensaio: avaliação e politicas públicas em educação. Rio de Janeiro, Fundação Cesgranrio, vol. 1-3, abr/jun, pp. 13-20.

TradTerm, 4(1), $1^{\circ}$ semestre de 1997, p. 69-84 